\title{
Arqueologia da Região do Maciço do Urucum e Pantanal de Corumbá-Ladário/MS
}

\author{
Emilia Mariko Kashimoto* \\ Gilson Rodolfo Martins ${ }^{* *}$
}

Este artigo mostra os resultados provenientes da pesquisa arqueológica, desenvolvida no período de 2000 a 2010 no maciço do Urucum, Corumbá, Mato Grosso do Sul Estado, Brasil. A análise que evoca a cultura material e a correlação entre a arqueologia e geocronologia: de grupos de indígenas, caracterizando um pre-cerâmico período colonial que corresponde a ocupações diferentes ceramista, Tupiguarani predominantemente na área (séculos VII-XV).O período de pós-descoberta cerâmico inclui os primeiros quatro séculos de contato da cultura indígena com a cultura europeia. As ocupações Tupiguarani chegaram ao fim, provavelmente, por causa da expansão do movimento de exploração desde o século XVI.

Palavras-chave: arqueologia do Maciço do Urucum, estado de Mato Grosso do Sul/Brasil, Pantanal Tupigurani.

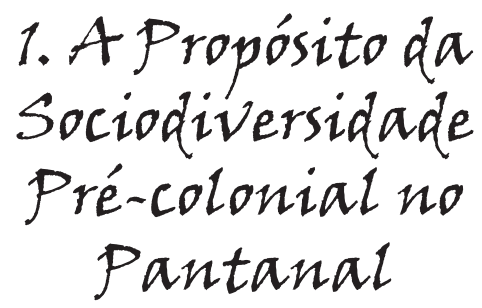

Pantanal é um conceito geográfico/espacial genérico e muito abrangente. Trata-se, na realidade, de uma área que cobre mais de 138 mil $\mathrm{km}^{2}$ e que, portanto, dificilmente seria homogênea. Seja a observação do ponto de vista das ciências huma-

\footnotetext{
* Doutora e Livre-Docente em Arqueologia Brasileira, coordenadora do Laboratório de Pesquisa Arqueológica (MuArq/PROPP/UFMS). emilia.kashimoto@pq.cnpq.br

** Doutor em Arqueologia, Chefe de Divisão do Museu de Arqueologia (MuArq/PROPP/UFMS). Gilson.martins@pq.cnpq.br
} 
This article shows the results originating from the archaeological research developed in the period from 2000 to 2010 in the maciço do Urucum, Corumbá, Mato Grosso do Sul State, Brasil. The analysis evokes the material culture and the correlation between archaeology and geochronology: from groups of indigenous characterizing a pre-colonial ceramic period which corresponds to different ceramist occupations, predominantly Tupiguarani in the area $\left(7^{\text {th }}-15^{\text {th }}\right.$ centuries $)$. The post- -discovery ceramic period includes the first four centuries of contact of the Indigenous culture with the European culture. The Tupiguarani occupations came to an end, probably, because of the expansion of the exploration movement since the $16^{\text {th }}$ century.

Keywords: Archaeology of the Maciço do Urucum, State of Mato Grosso do Sul/Brazil, Pantanal Tupigurani.

nas ou das geociências, na realidade são vários Pantanais, tanto em Mato Grosso do Sul, quanto em Mato Grosso. Para cada um desses Pantanais, portanto compartimentos ambientais específicos, existiram modelos de povoamento distintos, cujas relações homem-ambiente também foram diferenciadas. Os processos pré-históricos de povoamento, o que vale dizer também, as origens do homem no Pantanal, devem sempre ser tratados no plural. Por exemplo, o que aconteceu arqueologicamente na região das lagoas Mandioré, Gaíba e Uberaba, na região do chamado "Mar de Xaraés", foi um processo próprio desse contexto, não se repetindo na sua plenitude nas demais subunidades ambientais pantaneiras. A região setentrional do Pantanal, próxima ao município de Cáceres (MT), banhada pelo Alto Paraguai, onde os principais tributários são os rios Jauru, Cabaçal e Sepotuba, como outro exemplo, apresenta características geográficas e arqueológicas que, com certeza, não foram as mesmas da região do "Mar de Xaraés". Se englobarmos no conceito Pantanal a região da Serra da Bodoquena (MS) e a área dos municípios de Aquidauana (MS), Miranda (MS), Nioaque (MS) e Porto Murtinho (MS), também aí encontraremos horizontes arqueológicos próprios. Enfim, essa é a primeira constatação que as pesquisas arqueológicas, realizadas até o momento, nos permitem estabelecer.

O acima exposto permite afirmar que, como hoje, quando se observa uma diversidade étnica entre os povos indígenas viventes no Pantanal, tais como os Kadiwéu, Guató, Terena, Umotina e Bororo (povos com histórias próprias e sistemas culturais muito distintos), com relação ao passado pré-histórico e pré-colonial, a diversidade étnica era também uma realidade. 
Sobre o passado pré-histórico pantaneiro, portanto época anterior ao período de formação das culturas indígenas reconhecidas como tais etnograficamente, a única coisa que sabemos é que a ocupação humana pioneira do Pantanal deve ter ocorrido por meio de movimentos migratórios oriundos das regiões adjacentes, isto é, possivelmente do Planalto de Maracaju (MS), do Chaco (Paraguai/ Bolívia), do sul-amazônico, do Planalto Chiquitano (Bolívia) e do Cerrado (MT/ GO). Não está descartada a hipótese de que houve movimentos migratórios com origem andina. Nessa época, o acesso ao Pantanal teria sido orientado pelos cursos fluviais mais expressivos, sobretudo o alto curso dos rios Paraguai e Guaporé, ou ainda pelos tributários que deságuam no alto e médio curso do rio Paraguai, tais como o rio Jauru, Sepotuba, Cuiabá, Vermelho, Taquari, Aquidauana/ Miranda e Apa.

O Pantanal de Corumbá tem um ambiente geomorfológico típico de planícies fluviais, sujeitas a grandes inundações sazonais. As poucas áreas que se destacam acima do nível das águas na época da cheia são os topos de diques fluviais ou lacustres, localmente denominados "aterros", "cordilheiras" ou "capões-de-mato". Ainda hoje, os fazendeiros procuram esses locais para instalarem as sedes de fazendas, "mangueiros" e retiros, como na época colonial e pré-colonial, quando os mesmos locais eram escolhidos pelas populações indígenas como refúgios topográficos. É bem comum haver material arqueológico em altos topográficos do Pantanal. Somente nos arredores de Corumbá, por exemplo, já foram registrados mais de 250 sítios arqueológicos nesses "aterros" ou "capões-de-mato". Claro que nem todos os "capões" ou "aterros" são sítios arqueológicos, porém pode-se estimar que mais de 50\% destes locais contem material arqueológico, representado por vestígios materiais deixados por índios coloniais, pré-coloniais e até por caçadores-coletores-pescadores pré-históricos.

\section{Caçadores-coletores-pescadores pré- históricos no Pantanal}

Até o momento, a datação mais antiga relativa a presença do homem no Pantanal de Corumbá remonta a oito mil e duzentos anos atrás. Tal descoberta foi

\footnotetext{
${ }^{1}$ SCHMITZ, Pedro I. et alii. Aterros indígenas no pantanal do Mato Grosso do Sul. Pesquisas, 54. São Leopoldo: IAP/UNISINOS, 1998
} 
produto de um projeto de pesquisa desenvolvido pela equipe de Pedro Ignácio Schmitz, na década de 1990. Esse sítio, relativo ao assentamento de um grupo de caçadores/coletores/pescadores pré-indígenas, está localizado na área urbana de Ladário, inserido sobre um barranco da margem direita do rio Paraguai ${ }^{2}$. Ao que parece, trata-se de uma ocupação com perfil cultural característico do Holoceno arcaico (época iniciada há cerca de dez mil anos atrás, após o final do último período glacial), sugerindo a possibilidade da pretérita presença de paleoíndios naquela região. É muito provável que existam sítios mais antigos que esse no Pantanal, com idades superiores a dez mil anos, isto é, enquadrados geocronologicamente no final do Pleistoceno. Somente futuras pesquisas poderão confirmar, ou não, essas hipóteses.

Um fato que permite pensar a possibilidade da presença do homem durante o final do Pleistoceno no Pantanal é o resultado das pesquisas arqueológicas no município de Jangada, no oeste mato-grossense. Esses estudos, executados por uma equipe de pesquisadores franco-brasileiros, vinculados ao Museu Nacional de História Natural da França e ao Museu de Arqueologia e Etnologia da Universidade de São Paulo, apresentaram datações arqueológicas superiores a vinte e cinco mil anos atrás ${ }^{3}$. Em Mato Grosso do Sul, no alto curso do rio Sucuriú, contexto próximo às nascentes do rio Taquari, foram obtidas datações da presença humana há cerca de doze mil e quatrocentos anos ${ }^{4}$.

Esses dados levantam a hipótese de que é muito provável a presença do homem no Pantanal nesse período, mesmo considerando-se que as condições ambientais eram bem diferentes das de hoje. Provavelmente, a região pantaneira, na sua maior parte, deveria ser coberta por uma savana arbustiva. Nos compartimentos de relevo mais elevados, a vegetação aproximava-se a de uma caatinga. Nessa época, a vegetação era bem mais rala, a temperatura era alguns graus mais baixa que hoje: portanto, o clima era mais seco. Os humanos que aí viveram,

\footnotetext{
${ }^{2}$ SCHMITZ, P. I. et alii. Arqueologia do Pantanal do Mato Grosso do Sul. Pantanal 2000: Encontro Internacional de Integração Técnico-Científica para o Desenvolvimento Sustentável do Cerrado e Pantanal. Corumbá, 2000.

${ }^{3}$ VIALOU, Agueda e VIALOU, Denis. (org.) Pré-História do Mato Grosso. Volume 1. Santa Elina. São Paulo: Editora da Universidade de São Paulo, 2005.

${ }^{4}$ MARTINS, Gilson R. \& KASHIMOTO, Emília M. 12.000 anos: Arqueologia do povoamento humano no nordeste de Mato Grosso do Sul. Campo Grande: Life Editora/FCMS, 2012.
} 
desenvolveram comportamentos culturais ambientados a esse quadro natural. Talvez, certos traços da cultura material de algumas etnias chaquenhas atuais possam fornecer alguns subsídios para o conhecimento acerca desses horizontes culturais distantes no passado.

Após a ocupação arqueológica no Holoceno arcaico, identificada em Ladário, houve um período de quase quatro mil anos do qual não se tem, até o momento, registros arqueológicos, nesse contexto pantaneiro. Esse grande intervalo cronológico sem evidências arqueológicas não significa a inexistência da presença humana no Pantanal corumbaense. As condições ambientais, entre seis mil e quatro mil anos atrás, eram marcadas por temperaturas elevadas e intensa pluviosidade, características do período denominado optimum climático.

Por volta de quatro mil anos atrás, a população humana no Pantanal aumentou. Isso fica evidenciado pelo significativo número de sítios arqueológicos registrados, cujas datações remontam a esse período e épocas mais recentes. Esses sítios referem-se a bandos de caçadores/coletores/pescadores, denominados pré-cerâmicos, entre outras razões, para não serem confundidos com os índios horticultores e agricultores propriamente ditos. Os vestígios arqueológicos desse período cultural são encontrados com certa regularidade em aterros ou capões-de-mato do Pantanal. Tal configuração ambiental definiu a relação homem-ambiente tipicamente pantaneira de planície de inundação.

Os sítios arqueológicos que representam a presença pretérita de caçadores/ coletores/pescadores não-índios possuem pequena extensão. Geralmente são caracterizados por vestígios de acampamentos temporários, exibem itens da cultura material tais como, machados de pedra, esqueletos/sepultamentos, restos de alimentação, adornos corporais confeccionados sobre ossos, conchas ou rochas, raras pontas de projeteis confeccionadas sobre rochas e poucas ferramentas de pedra lascada. Alguns locais, além de servirem como áreas de acampamentos, também eram utilizados para a realização de rituais simbólicos.

No Pantanal existe evidências arqueológicas de representações simbólicas como os painéis com arte rupestre parietal (pinturas e gravuras feitas nas paredes de abrigos sob rocha) presentes na região de Cáceres (MT), ou ainda na "Cidade de Pedra" - formação rochosa próxima à margem direita do rio Vermelho (Rondonópolis, MT), entre vários outros. Na área municipal de Co- 
rumbá, MS, ocorrem gravuras feitas em afloramentos litológicos (lajedos) na morraria do Caracará, localizadas nas cercanias das lagoas Gaíba, Uberaba e Mandioré, assim como aquelas registradas no entorno do maciço do Urucum.

Os estudos arqueológicos na região do Urucum tiveram início no ano de 1976, quando o pesquisador Afonso de Moraes Passos, integrante do extinto Instituto de Pré-história da Universidade de São Paulo, desenvolveu uma tese de livre-docência sobre os petroglifos existentes na Fazenda Banda Alta, localizada na face ocidental do maciço.

Os lajedos de hematita situados na base da morraria do Urucum, em Corumbá, foram utilizados por populações pré-históricas para gravações de representações simbólicas complexas. Face à associação dessas inscrições com a simbologia dos rios, corixos, ilhas e aterros das áreas alagadas, Girelli ${ }^{5}$ levantou a hipótese de se tratar de arte produzida pelos construtores de aterros nas áreas alagadiças do pantanal.

Em Corumbá, o sítio MS-CP-03 (ver figura 1) teve sua relevância patrimonial reafirmada ao ser inserido na lista de Geosítios do Geopark Bodoquena/ Pantanal.

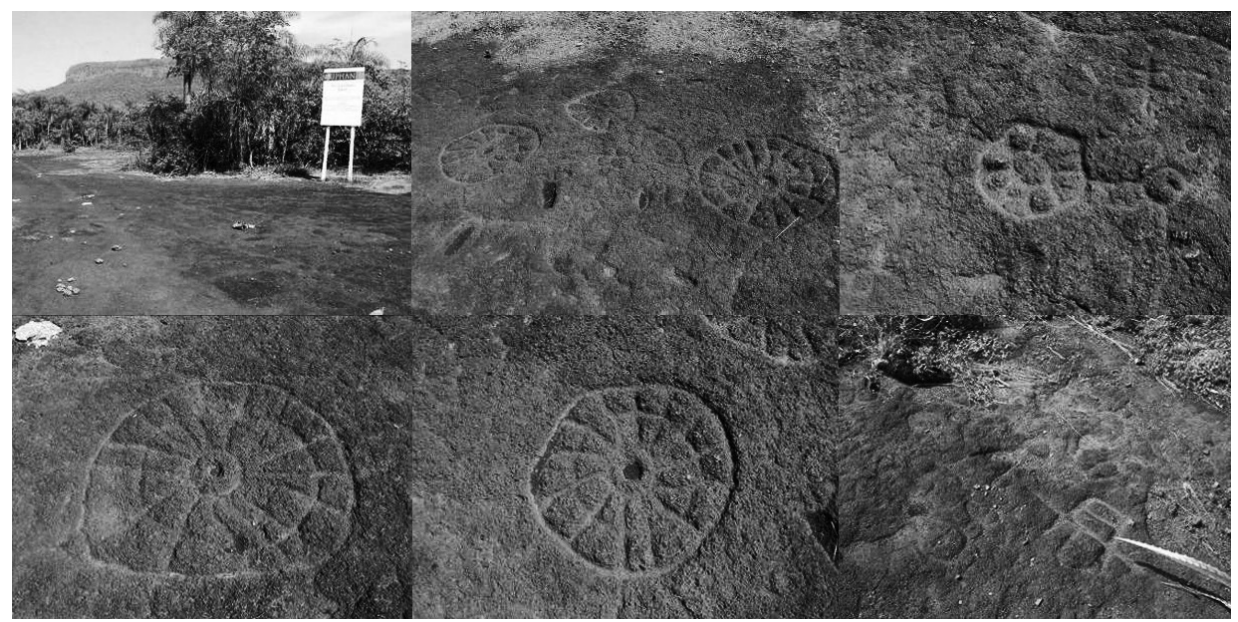

Figura 1: Sítio arqueológico MS-CP-03 - Geosítio do GEOPARK Bodoquena/Pantanal, com detalhes de alguns petroglifos

${ }^{5}$ GIRELLI, Maribel. Lajedos com gravuras na região de Corumbá, MS. Dissertação de Mestrado apresentada ao IAP/UNISINOS. São Leopoldo, 1994. 


\section{Os Indigenas Horticultores/agricultores Ceramistas Pré-coloniais no Pantanal}

Após o optimum climático, a temperatura média teve uma pequena regressão e, desde dois mil anos atrás, vem mantendo-se, aproximadamente, nos padrões atuais. As condições climáticas estabilizadas influenciaram o perfil ambiental da região pantaneira caracterizando-a tal como a conhecemos hoje.

Por volta de dois mil e duzentos anos atrás, surgiram as primeiras evidências da presença de grupos ceramistas no Pantanal, o que pode significar o início do processo formativo das etnias indígenas conhecidas tanto pela arqueologia como pela etnografia. Isso significa uma mudança cultural bastante significativa, a qual pode ter tido origens culturais endógenas e/ou exógenas.

Existiram grupos indígenas ceramistas que se estabeleceram próximos ao rio Paraguai, em capões-de-mato, nas áreas sazonalmente inundáveis, assim como aqueles que fizeram seus assentamentos nos locais topograficamente mais elevados, em lugares não sujeitos às inundações periódicas, como o são os terraços onde estão as cidades de Corumbá (MS) e Cáceres (MT), bem como Aquidauana (MS), Miranda (MS), entre outras. Desta maneira, podemos perceber que houve, no passado pantaneiro, uma pluralidade cultural acentuada, integrada aos diferentes compartimentos ambientais.

Nas áreas não inundáveis do Pantanal há vestígios remanescentes de grandes aldeamentos indígenas que existiram no passado pré-colonial e colonial, bem como alguns testemunhos de etnias extintas antes ou depois da chegada do colonizador ibérico. Nos registros arqueológicos encontram-se amostras de cerâmica com padrões diversificados, seja quanto à sua decoração e/ou quanto à tecnologia de confecção. Isto indica a existência de povos culturalmente diferenciados e com processos históricos próprios. Nos sítios da tradição arqueológica Descalvado a cerâmica evidencia a existência de um povo que habitou o contexto entre as lagoas Uberaba, Gaíba e Mandioré (o denominado "Mar de Xaraés") e o município de Cáceres. Os vestígios arqueológicos já descobertos indicam que havia grandes aldeias indígenas, algumas das quais foram observadas e descritas pelos conquistadores europeus no século XVI. Em cada uma delas podem ter vivido até duas ou três mil pessoas. Outros tipos de sítios arqueológicos pantaneiros, também referentes a assentamentos de indígenas agricultores, apresentam dimensões menores e referenciam outros grupos étnicos. 


\subsection{Siios Arqueológicos na Baixa Vertente da Morraria do Urucum, Corumbá Ladário/MS}

A região do maciço do Urucum localiza-se nas áreas municipais de Corumbá e Ladário/MS, constituindo-se em uma paisagem singular na geomorfologia da planície sedimentar do Pantanal. Nas baixas vertentes da morraria (piemonte), não inundáveis, os solos férteis foram substrato para o desenvolvimento de uma densa floresta, bem como palco de distintos processos de povoamento pré-coloniais e históricos. Esse ambiente foi preferencialmente ocupado por povos agricultores Tupiguarani pré-coloniais.

Essa região foi objeto de pesquisas arqueológicas a partir de 1990, quando pesquisadores do Instituto Anchietano de Pesquisa/UNISINOS e do campus do Pantanal/UFMS, (CPAN) coordenados pelo Prof. Dr. Pedro Ignácio Schmitz, deram início ao Projeto Corumbá. No âmbito desse projeto, o Prof. Dr. José Luiz S. Peixoto, da UFMS/CPAN, desenvolveu uma dissertação de mestrado relativa à descoberta de vinte e dois sítios arqueológicos na região do Maciço do Urucum, típicos da tradição arqueológica Tupiguarani ${ }^{6}$.

A partir da década de 2000, com a perspectiva de implantação/renovação de obras de engenharia no maciço do Urucum foram realizados projetos de mitigação dos impactos consequentes. Novos sítios foram descobertos, ampliando-se assim a cartografia arqueológica da região o conhecimento arqueológico correlato. Com base nas análises provenientes do cruzamento de dados geoambientais e cartográficos com as informações arqueológicas previamente disponíveis, aplicou-se uma metodologia de levantamento e prospecção arqueológica que resultou na ampliação de pontos/locais pesquisados e no registro dos sítios arqueológicos, Córrego Arigolândia 1 (AL1), Baía do Mato Grande 1 (MG1), Córrego Urucum 1 (UR1), Córrego Urucum 2 (UR2), Córrego Urucum 3 (UR3), Córrego Urucum 4 (UR4), Córrego Urucum 7 (UR7, ou MS-CP-42), Córrego Urucum 8 (UR8), Córrego Urucum 9 (UR9) (ver figuras 2 e 3).

\footnotetext{
${ }^{6}$ PEIXOTO, José L. S. A ocupação tupiguarani na borda Oeste do Patanal Sul-mato-grossense. Dissertação de Mestrado apresentada à PUC/RS. Porto Alegre, 1995; PEIXOTO, José L. S.; BEZERRA, Maria A.; ISQUIERDO, Sérgio W. G. Padrão de Assentamento das populações indígenas pré-históricas do Pantanal sul-mato-grossense. In: SIMPÓSIO SOBRE RECURSOS NATURAIS E SÓCIO-ECONÕMICOS DO PANTANAL, 2, 1996, Corumbá. Manejo e Conservação. ANAIS., Corumbá:EMBRAPA PANTANAL, 1999.
} 


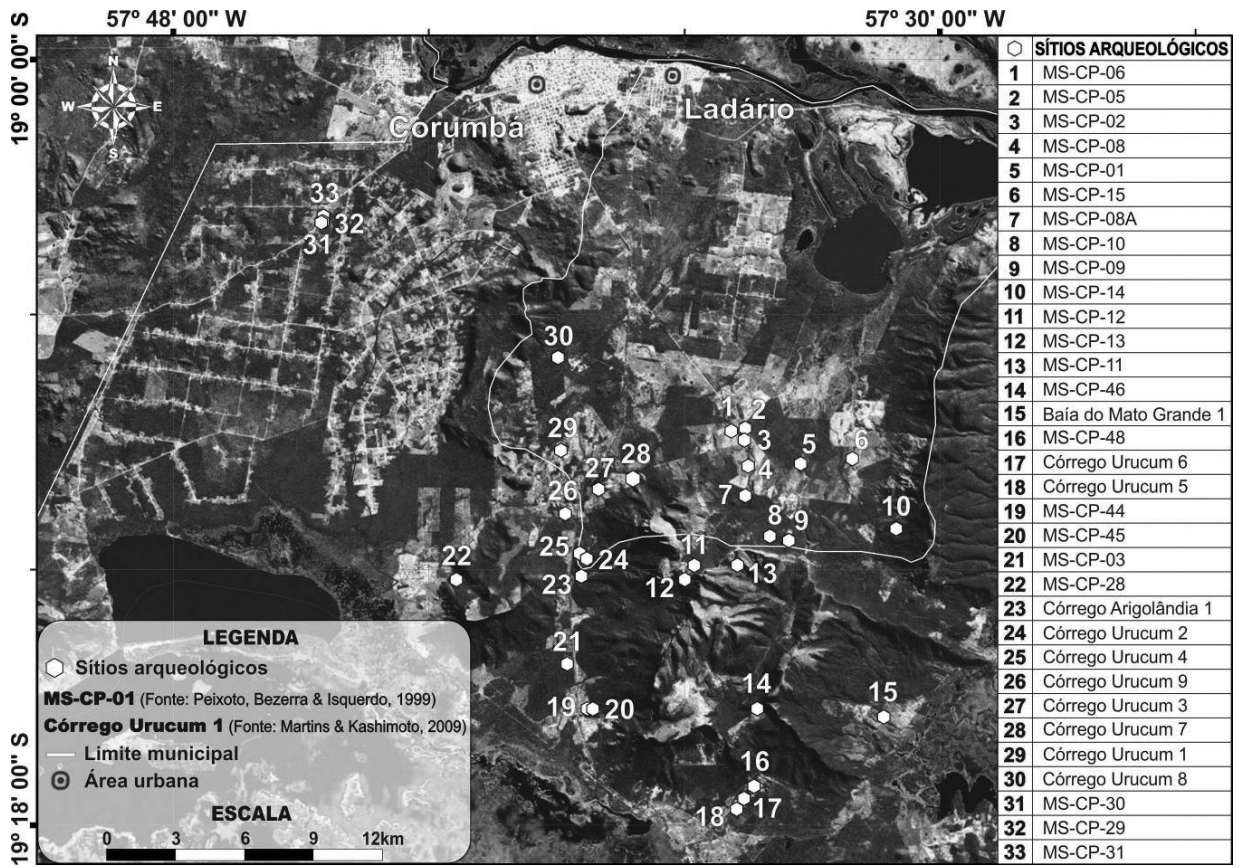

Figura 2: Sítios arqueológicos localizados no contexto do maciço do Urucum, Corumbá-Ladário/MS

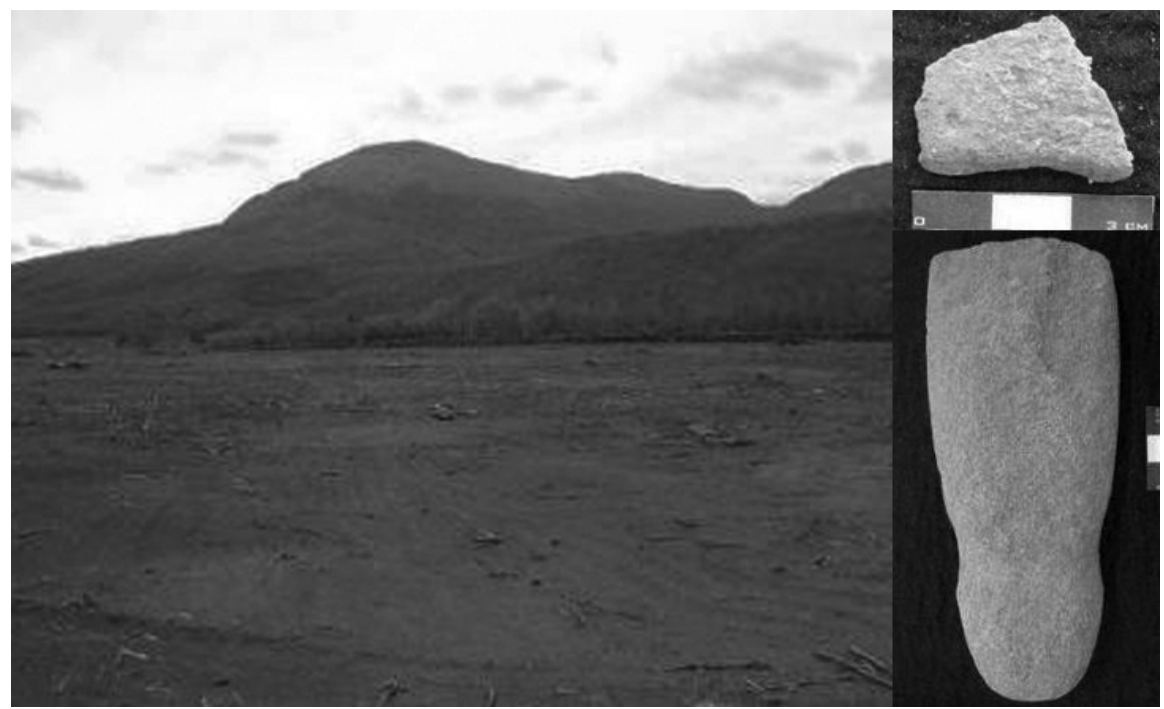

Figura 3: Sítio Córrego Urucum 4 (pré-colonial), fragmento de cerâmica e lâmina de machado polida nele localizados. 


\subsection{Escavações de Sítios Arqueológicos no contexto do Maciço do Urucum}

A Arqueologia estuda as culturas pretéritas enfatizando a análise de sua cultura material por meio dos vestígios arqueológicos e das características ambientais dos locais selecionados para o estabelecimento humano - os sítios arqueológicos. As escavações arqueológicas realizadas objetivaram identificar os elementos que contribuam para análises acerca do comportamento cultural, econômico e social dos grupos humanos pretéritos que aí viveram. Ao mesmo tempo buscou-se ampliar o conhecimento acerca das ocupações arqueológicas na baixa vertente da morraria do Urucum.

Foram realizadas escavações arqueológicas nos sítios Córrego Urucum 1, Córrego Arigolândia 1, Córrego Urucum 7, Córrego Urucum 8 e Córrego Piraputanga/Corumbá 1 , motivadas pelas seguintes perspectivas:

- os locais pesquisados constituem-se em sítios arqueológicos a céu aberto, com vestígios cerâmicos, passíveis de serem afetados por grandes empreendimentos de mineração na área estudada;

- esses sítios constituem-se em locais potencialmente informativos acerca do povoamento regional pelos povos agricultores ceramistas Tupiguarani pretéritos no Pantanal, aptos a serem analisados comparativamente com os vestígios evidenciados no entorno.

Considerando-se as expressivas extensões espaciais dos sítios arqueológicos estudados foram selecionados os locais com maior densidade de vestígios arqueológicos para a realização das escavações arqueológicas. As escavações contemplaram os contextos arqueológicos superficiais e subsuperficiais por meio de limpeza de superfície, escavação de trincheiras e áreas de decapagem7.

As datações, apresentadas adiante foram obtidas a partir dos seguintes materiais e métodos: as amostras de carvão de fogueiras arqueológicas foram datadas, pelo método do Carbono 14, no laboratório de física da Beta Analytic Inc. (Miami/Flórida); as amostras de cerâmica arqueológica foram datadas pelo método da termoluminescência no Laboratório de Vidros e Datações da Faculdade

\footnotetext{
${ }^{7}$ MARTINS, Gilson R. \& KASHIMOTO, Emília M. Fazenda Urucum, Corumbá, Brasil: Uma Estratigrafia de Paisagens Culturais. Simpósio: Paisajes arquitectónicos del pasado americano: investigación y gestion. In: 53 CONGRESSO INTERNACIONAL DE AMERICANISTAS, CD-ROM, 2009, Cidade do México. Atas... Cidade do México: Universidad Católica de México, 2009.
} 


\subsubsection{Sitio Arqueológico Córrego urucum 1 (UR1): Arqueologia de uma Aldeia Tupiguarani - Séculos VI a IX}

No sítio Córrego Urucum 1 (UR1) foram escavadas, uma trincheira com $16,00 \mathrm{~m}$ de comprimento, $1,00 \mathrm{~m}$ de largura e $0,40 \mathrm{~m}$ de profundidade e duas áreas de decapagem com as dimensões $10,00 \mathrm{~m} \times 2,00 \mathrm{~m}$ e $0,50 \mathrm{~m}$ de profundidade ${ }^{8}$.

A escavação evidenciou que o sítio é o remanescente de uma extinta aldeia utilitária da cerâmica arqueológica Tupiguarani, dos quais restaram fragmentos cerâmicos com decoração corrugada, engobada ou pintada, além de líticos lascados (lascas e fragmentos de lascas), associados a fragmentos cerâmicos com decoração impressa por meio do uso de cordinhas de fibras vegetais, possivelmente relacionados à uma cultura pretérita de origem chaquenha/Aruak (ver figura 4).

Essa diversidade de padrões decorativos das peças cerâmicas do sítio UR1 sugere contatos interculturais ou diversidade de ocupações indígenas pretéritas na área. Esta interpretação coaduna com a efetuada por Peixoto": "O contato entre o Tupiguarani e os grupos da área de inundação (Aterros) é possivel, pois alguns fragmentos cerâmicos pertencentes aos aterros foram coletados junto aos sítios Tupiguarani (MS-CP-13, MS-CP-42 e MS-CP-44), apontando para um possivel contato elou contemporaneidade na ocupação deste território."

Entre os resultados obtidos nessa escavação, destaca-se a datação de carvões de uma fogueira cujo resultado indica que uma ocupação Tupiguarani no local ocorreu no intervalo entre os séculos VII a IX (amostra Beta-240841).

Esse sítio talvez represente uma das primeiras ocupações de agrupamentos Tupiguarani no maciço do Urucum.

\footnotetext{
${ }^{8}$ MARTINS, Gilson R. \& KASHIMOTO, Emília M. Mitigação de impactos sobre o patrimônio arqueológico na área de influência da Mina 63, em Corumbá/MS: escavação do sítio Urucum 1. Campo Grande: Fundação Candido Rondon/MMX - Metálicos Corumbá Ltda, 2008. (não publicado)

${ }^{9}$ PEIXOTO, José L. S. A ocupação..., Op. cit., p. 103.
} 


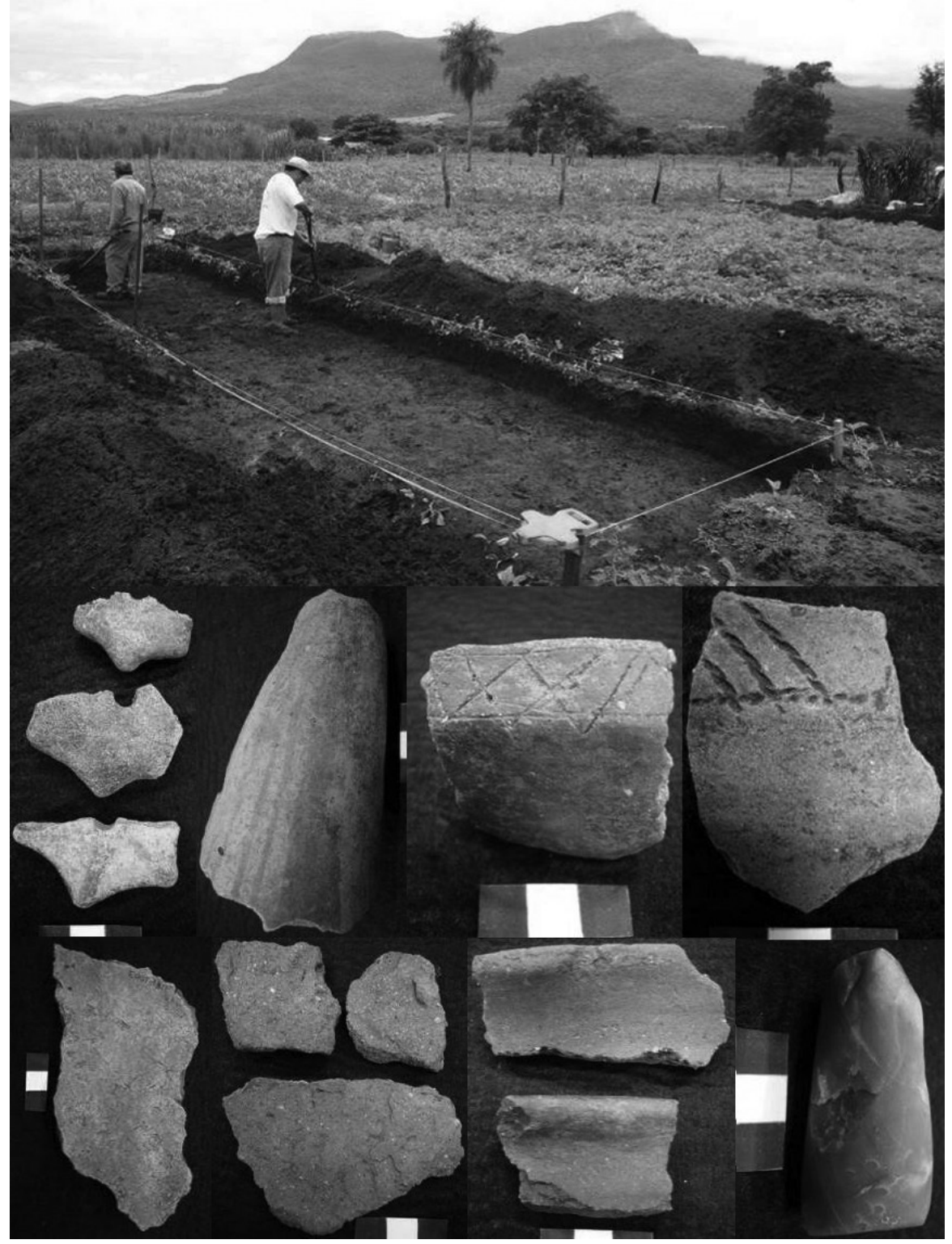

Figura 4: Escavação da área de decapagem "1" no sítio UR1 e fragmentos de cerâmica (com pintura e furos, com pintura em linhas vermelhas, com linhas incisas, com impressão de corda, com engobo vermelho, corrugada e lisa) e lítico polido. 


\subsubsection{Sitio Arqueológico Córrego Arigolândia 1 (AL1): Arqueologia de uma Aldeia Tupiguarani - Séculos XI a XII}

As escavações arqueológicas no sítio Córrego Arigolândia 1 (AL1) abrangeram abertura de quatro trincheiras com $1,00 \mathrm{~m}$ de largura e $0,50 \mathrm{~m}$ de profundidade, sendo que as extensões atingiram, em duas trincheiras, $30,00 \mathrm{~m}$ e, em outras duas, $15,00 \mathrm{~m}$ de comprimento ${ }^{10}$.

Durante as escavações no sítio arqueológico AL1 foi encontrada uma representativa quantidade de fragmentos de cerâmica arqueológica, estando as mesmas em seus respectivos níveis de deposição original. Do ponto de vista científico, os dados coletados, por meio da bibliografia consultada, dos trabalhos de campo e laboratório e as relações internas entre eles, nos permitiram inferir que o sítio arqueológico AL1 é o espaço referente a uma antiga aldeia de índios produtores da cerâmica arqueológica Tupiguarani, que viveram em torno da morraria do Urucum em tempos pré-coloniais.

Os fragmentos de cerâmica coletados são, predominantemente, de paredes de recipientes lisos, sem decoração, seguidos por fragmentos com decoração externa corrugada, ungulada e pintada; foi realizada a reconstituição de uma vasilha cerâmica desse sítio (ver figura 5). Quanto ao material lítico, no sítio AL1 foram localizadas menos de uma dezena de peças, dentre os quais pode-se destacar uma mão-de-pilão e um percutor, entre lascas e fragmentos de rocha. Deve-se ressaltar que a petrografia da região de Corumbá não se caracteriza pela plena disponibilidade de rochas aptas ao lascamento arqueológico.

As estruturas de combustão também foram raras, porém na trincheira 1 , metro 4 , profundidade de 0,30 a $0,40 \mathrm{~m}$, foi evidenciada uma fogueira arqueológica, no nível mais profundo de ocorrência de vestígios cerâmicos, praticamente sobre o substrato rochoso. Essa amostra de carvão arqueológico (Beta-218203) resultou na datação calibrada de 1010 a 1180 AD, ou seja,

${ }^{10}$ MARTINS, Gilson R. \& KASHIMOTO, Emília M. Arqueologia preventiva na área impactada pela implantação da Mina 63, Corumbá/MS. Campo Grande: FAPEC/MMX Corumbá Mineração Ltda., 2006. (não publicado) 
a ocupação humana do local ocorreu em data situada no intervalo entre os séculos XI a XII.

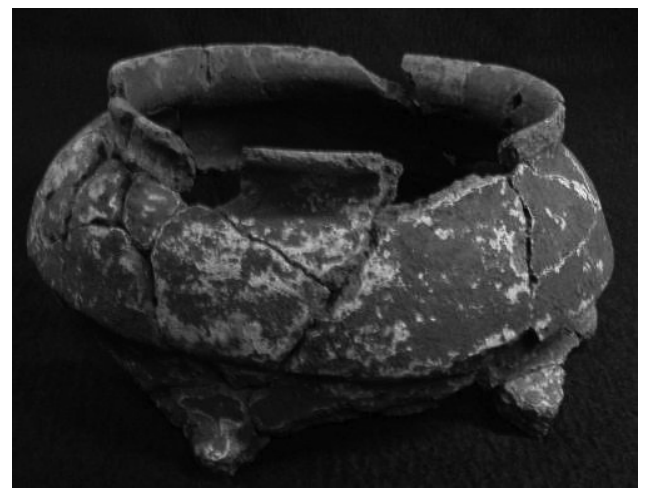

Figura 5: Peça cerâmica coletada na escavação do sítio AL1, reconstituída em laboratório. A peça está exposta no Museu de História do Pantanal (MUHPAN).

\subsubsection{Sitio Córrego urucum 7 (UR7) - Arqueologia de uma Aldeia Tupiguarani - Séculos XV ao XVI}

No sítio Córrego Urucum 7 (UR7) foram escavadas: duas trincheiras de 10,00m de comprimento, 1,00m de largura e 0,50m de profundidade; duas áreas de decapagem com as dimensões $2,00 \mathrm{~m}$ x $2,00 \mathrm{~m}$, profundidades de $0,80 \mathrm{~m}$ e $0,30 \mathrm{~m}^{11}$. Foram coletados numerosos vestígios remanescentes da cultura material dessa realidade pretérita, tais como, uma urna cerâmica, fragmentos cerâmicos com decoração corrugada, engobada e pintada, além de líticos polidos (ver figuras 6 e 7). Assim, como no sítio Córrego Urucum 1, esses vestígios estão associados a fragmentos de cerâmica decorada por meio de impressão de cordinhas de fibras vegetais, possivelmente relacionados às culturas pretéritas de origem chaquenha/Aruak, sugerindo, portanto, contatos interculturais ou distintas e sucessivas ocupações indígenas pré-coloniais no mesmo local.

\footnotetext{
${ }^{11}$ MARTINS, Gilson R. \& KASHIMOTO, Emília M. Diagnóstico Arqueológico da área a ser impactada pela ampliação da área de lavra e beneficiamento de ferro e manganês da Urucum Mineração, Corumbá, MS. Campo Grande: FAPEC \& Golder Associates do Brasil, 2006 (não publicado); MARTINS, Gilson R. et al. Relatório final do projeto de pesquisa: arqueologia preventiva na área de estocagem da Urucum Mineração S/A, Corumbá/MS. Campo Grande: FAPEC/ Urucum Mineração S/A, 2009.
} 
O sítio UR7 constituiu-se numa aldeia pré-colonial, correlacionável ao conjunto de sítios Tupiguarani do maciço do Urucum, compondo um complexo de sítios possivelmente integrados na mesma conjuntura arqueológica. Uma amostra de carvão de fogueira arqueológica, coletada na trincheira 1, profundidade de 0,40 a 0,50m foi datada em 1420 a 1540 AD (Beta-247319), cronologia situada no intervalo entre os séculos XV ao XVI.

Durante esses estudos constatou-se, portanto, que a área em tela foi o espaço onde, no passado pré-colonial, houve um grande aldeamento de índios associados à tradição da cerâmica arqueológica Tupiguarani, com contatos com a tecnologia cerâmica dos índios Guaná.

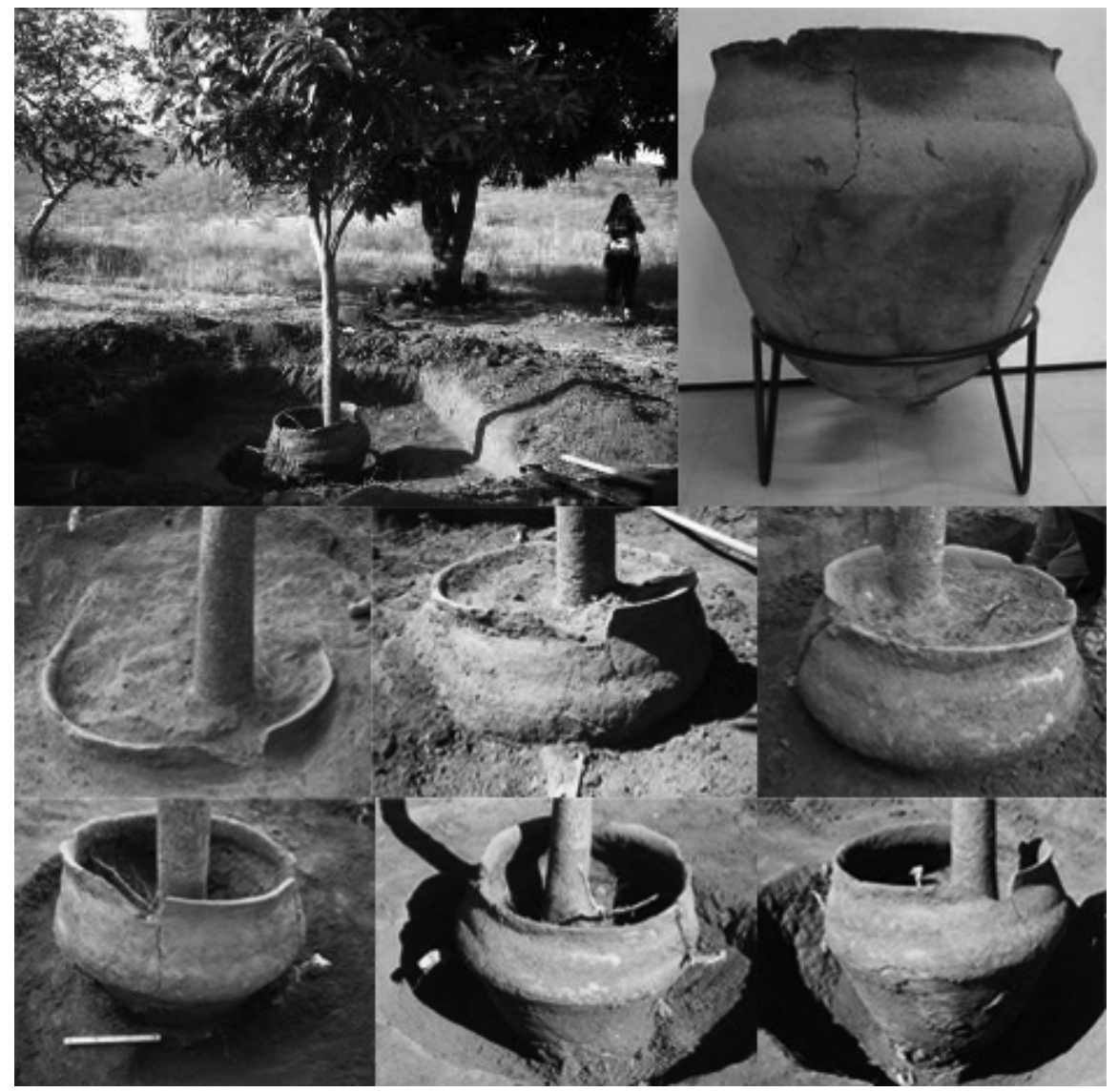

Figura 6: Escavação da área de decapagem "1" no sítio UR7 e a sequência da evidenciação da vasilha cerâmica arqueológica Tupiguarani; no canto superior direito, a mesma urna após ser restaurada no MuArq/UFMS 


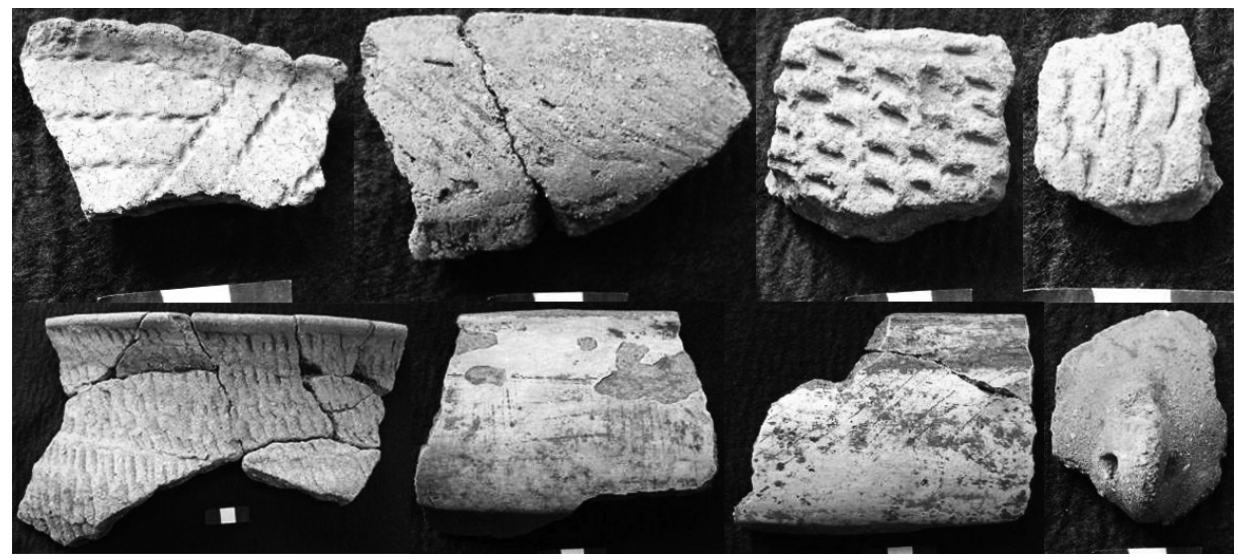

Figura 7: Fragmentos de cerâmica do sítio UR7 com diferentes padrões decorativos: com impressão de cordinha, escovada, espatulada, ungulada, corrugada, pintada (dois fragmentos) e alça com furo de suspensão.

No sítio Córrego Urucum 3 (UR3), situado a cerca de 1,8 km de distância do sítio UR7, foram coletadas três amostras de cerâmica datadas em 500 $\pm 60,440 \pm 00$ e $410 \pm 50$, ou seja, trata-se de uma ocupação que ocorreu entre os séculos XV e XVI. Esse resultado coaduna-se com aquele obtido no sítio UR7, isto é, foram aldeias contemporâneas no mesmo horizonte cultural Tupiguarani.

\subsubsection{Sitio Arqueológico Urucum 8 (UR8) - Arqueologia de uma Aldeia Tupiguarani - Séculos XV a XIX}

Durante os trabalhos de levantamento e prospecção arqueológica foram coletados no sítio Córrego Urucum 8 (UR8), diversos vestígios arqueológicos, tais como, fragmentos de cerâmica, lâminas de machados líticos polidos, carvões arqueológicos, assim como foi evidenciado e coletado um esqueleto humano parcialmente desarticulado, o qual foi devidamente consolidado e protegido para o transporte até o laboratório do MuArq/UFMS (ver figura 8). O material ar- 
queológico indica tratar-se do um local de um antigo aldeamento Tupiguarani ${ }^{12}$. Com as datações realizadas foram obtidos os seguintes resultados cronológicos:

- Osso humano $($ Beta -298153$)=1470$ A 1650 (séc. XV a XVII)

- Carvão(Beta - 298155) = 1650 A 1890 (séc. XVII a XIX)

- Carvão (Beta - 298156) = 1670 A 1780 (séc. XVII a XVIII)

Os resultados das datações indicam tratar-se de uma ocupação Tupiguarani entre os séculos XV e XIX. A composição calcárea do solo promoveu condições de preservação do esqueleto humano arqueológico, provavelmente Tupiguarani, ocorrência rara nas condições pedológicas de Mato Grosso do Sul. No entanto, um esclarecimento mais acurado dessa contextualidade arqueológica dependerá da continuidade das pesquisas no local.

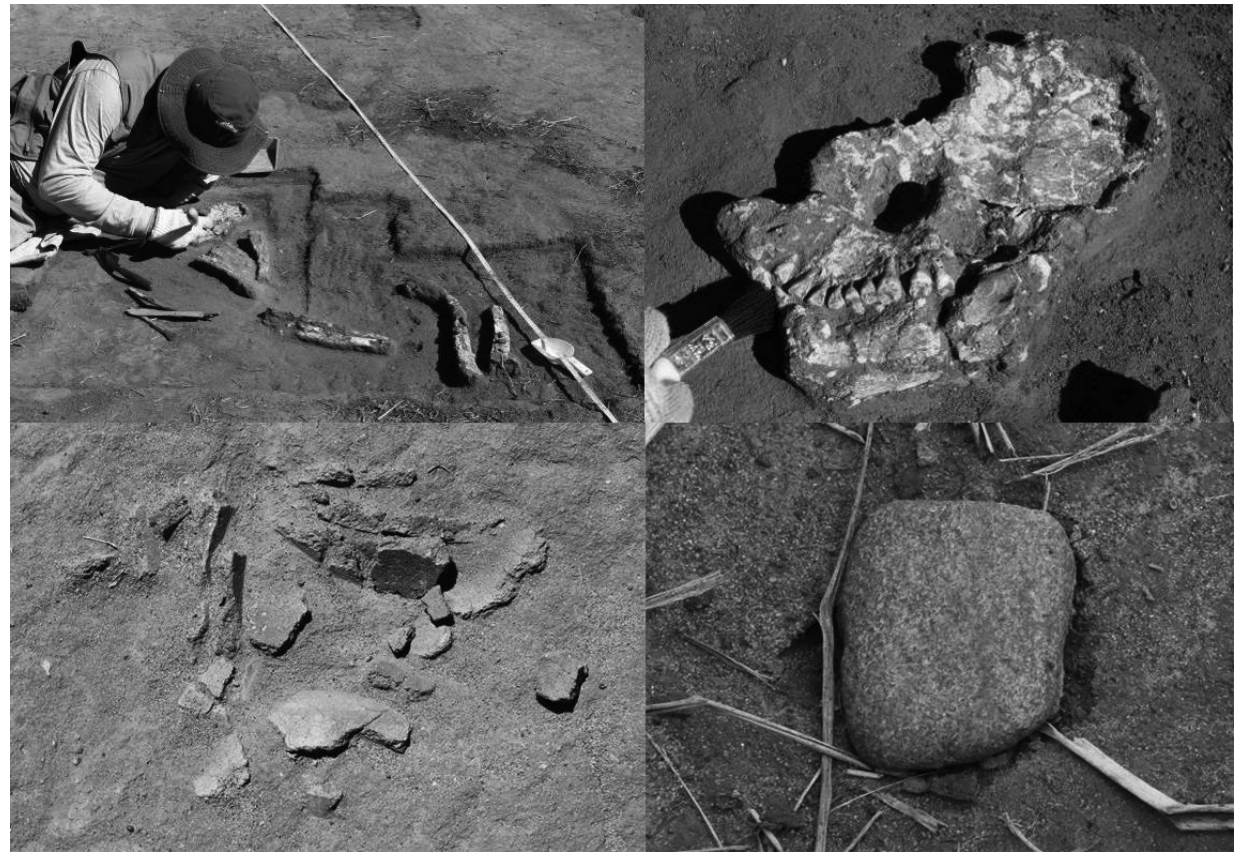

Figura 8: Escavação do esqueleto humano no sítio UR8, fragmentos de cerâmica e lâmina de machado polida

${ }^{12}$ MARTINS, Gilson R. \& KASHIMOTO, Emilia M. Arqueologia preventiva na área a ser impactada pela instalação da Mina Laginha, Corumbá/MS. Campo Grande: Votorantim Cimentos Brasil Ltda./Ecoguias Soluções Ambientais, 2011. (não publicado) 


\subsubsection{Sitio Arqueológico Córrego}

Piraputanga/Corumba 1 (CB1): uma

Aldeia Indígena da Tradição Pantanal?

O sítio arqueológico Córrego Piraputanga/Corumbá 1 (CB1) localiza-se entre a lagoa do Jacadigo e a morraria. A lagoa deve ter exercido forte atração locacional, sendo o seu contexto ambiental relevante na estratégia de sobrevivência dos habitantes do sítio. A opção pela instalação habitacional nas proximidades da morraria foi influenciada pela topografia mais elevada, portanto imune às inundações, com solo, temperatura e umidade atrativos ao estabelecimento humano indígena. A proximidade do córrego Piraputanga, possuidor de volume de água considerável e permanente, oriundo de nascentes na morraria, portanto, com água corrente e fresca, deve ter sido fundamental no abastecimento hídrico, tanto para o consumo pessoal como para as atividades agrícolas daquela população.

Foram escavadas quatro trincheiras, cada uma delas com as seguintes dimensões: $10,00 \mathrm{~m}$ de comprimento; $1,00 \mathrm{~m}$ de largura e $0,50 \mathrm{~m}$ de profundidade ${ }^{13}$. Nas escavações localizaram-se carvões remanescentes de diversas fogueiras. A maior parte dos fragmentos de cerâmica evidenciados é de paredes de recipientes lisos, sem decoração externa ou interna; uma vasilha cerâmica inteira foi coletada na escavação arqueológica (ver figura 9). Do mesmo modo como nos sítios arqueológicos UR1 e UR7, no sítio CB1 alguns poucos fragmentos apresentam uma decoração plástica feita pela impressão de cordinhas de fibra vegetal, característica típica da cerâmica Aruak/Guaná-Chané, bem como de outras etnias de origem chaquenha, como os Guaicuru. Um número bem reduzido de fragmentos de paredes de recipientes apresentou decoração plástica corrugada, semelhante àquela da cerâmica da Tradição Pantanal. Particularmente chamou atenção um fragmento de parede que apresenta resíduo de uma aplicação em alto relevo de uma figura zoomorfa, provavelmente um réptil (lagarto ou jacaré). A decoração com pintura ou engobo branco na parte interna ocorreu em menos de uma dezena de fragmentos, o que nos leva a pensar que são intrusivos. Outros remanescentes da cultura material localizados foram uma lâmina de machado lítico polido e um suporte de jirau de madeira.

\footnotetext{
${ }^{13}$ MARTINS, Gilson R. \& KASHIMOTO, Emília M. Relatório final do projeto: Arqueologia preventiva na área impactada pela implantação da Usina Siderúrgica de Ferro Gusa, Corumbá/MS. Campo Grande: FAPEC/MMX Mineração e Metálicos, 2007. (não publicado)
} 
Um aspecto a ser ressaltado é o fato de que na região da baixa vertente da morraria do Urucum, os sítios da tradição Tupiguarani, pelo conhecimento que se possui no momento, são predominantes. Não se enquadrando nessa tradição, o sítio Córrego Piraputanga/Corumbá 1 sugere novas possibilidades interpretativas acerca das realidades arqueológicas dessa região, ou seja, a sua ocupação também por populações integrantes da tradição arqueológica Pantanal, cujo território típico é o dos capões de mato das áreas inundáveis da planície pantaneira, ou talvez da tradição Descavaldo.

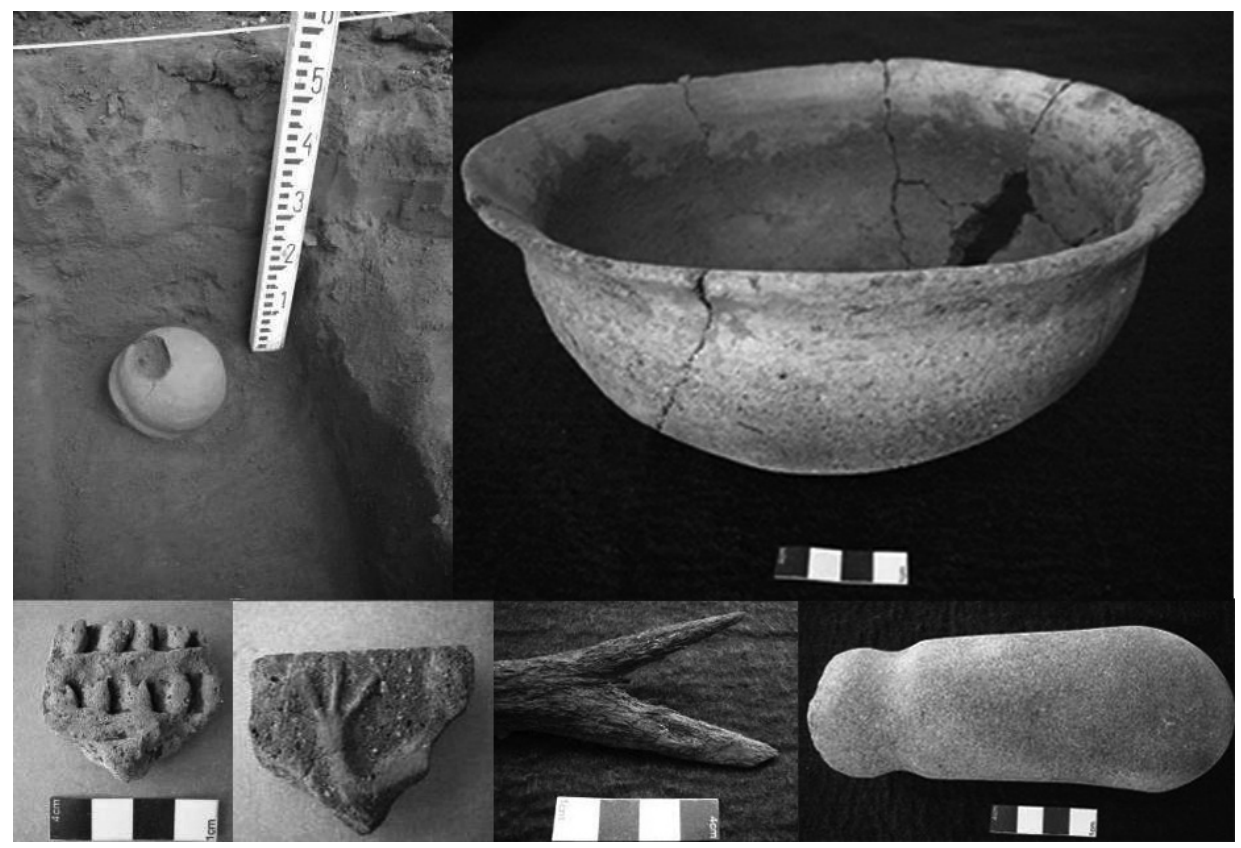

Figura 9: Sítio CB1 -vasilha cerâmica evidenciada na escavação arqueológica e a mesma após a restauração; na linha inferior, fragmentos de cerâmica, jirau e lâmina de machado polida

\section{Arqueologia Históricano Pantanal de Corumbá}

Além das descobertas anteriormente elencadas, alguns sítios podem ser incluídos na modalidade científica intitulada "Arqueologia Histórica". Possuímos diversas evidências materiais de sociedades coloniais, castelhana/paraguaia e luso/brasileira no Pantanal, as quais permitem, inclusive, o estudo dos primei- 
ros encontros/confrontos entre índios e "brancos" e das relações interétnicas entre o colonizador europeu e os grupos nativos aqui existentes. Podemos incluir nos itens com interessante para a Arqueologia Histórica, desde fortes coloniais, como é o caso do Forte Coimbra, em Corumbá, e do Forte de Miranda, bem como estruturas arquitetônicas urbanas, com perfil histórico, nas cidades de Cáceres, Nioaque, Miranda, Corumbá e Ladário, ou ainda, as ruínas das missões religiosas, em áreas indígenas no Pantanal, nos séculos XVII e XVIII. Os fortes, por exemplo, são estruturas passíveis de uma pesquisa arqueológica com objetivos históricos ou etno-históricos.

Entre as mais expressivas missões indígenas coloniais podemos citar as missões jesuíticas do Itatim, no Pantanal Sul, as quais abrangeram a região entre os rios Taquari e Apa, e entre a Serra de Maracaju e o rio Paraguai. As missões jesuíticas tentaram catequizar os índios Guarani que viveram no interflúvio entre os rios Miranda e Aquidauana, como também os Guaicuru e outros grupos que viviam em Corumbá, posteriormente extintos. Porém, os resultados foram efêmeros.

Sobre os períodos mais recentes, a Arqueologia pode contemplar contextos como os da Guerra do Paraguai, de fazendas pioneiras da pecuária, etc. Existe, por exemplo, vestígios abundantes dos episódios que envolveram a invasão paraguaia em Mato Grosso do Sul, como cemitérios, trincheiras, trilhas, armamentos, etc.

A complexidade etnográfica no Pantanal era muito significativa por ocasião dos primeiros trinta anos de conquista da América, no século XVI. Antes da chegada dos "descobridores coloniais" viviam na região pantaneira algumas centenas de milhares de índios. Os primeiros conquistadores ibéricos chegaram no Pantanal entre 1523 e 1525. A presença do primeiro "branco" europeu, ou não-índio no Pantanal, registrada pela História foi a do naufrago/conquistador português, Aleixo Garcia - o primeiro homem "branco" a percorrer e a morrer no Pantanal. Depois dele, a próxima investida do sistema colonial europeu sobre o Pantanal se fez por meio de uma grande expedição conquistadora e colonizadora. Ela foi comandada pelo adelantado espanhol, Pedro de Mendoza, o grande conquistador do rio da Prata e Paraguai, isto em 1535. Mendoza veio com uma grande expedição com o objetivo de explorar o alto rio Paraguai. Essa expedição era motivada, sobretudo, pelos mitos indígenas referentes à existência de uma "Serra de Prata", do "Eldorado" e de cidades riquíssimas com grandes jazidas de metais preciosos. Esses mitos eram, na realidade, fundamentados na existência 
concreta de minas de prata na Bolívia (Potosí) e no Império Inca. Com certeza, nessa época, havia centenas, talvez milhares de índios vivendo no Pantanal e que portavam objetos/adornos de prata, daí o nome bacia Platina ou ainda Argentina. O próprio Aleixo Garcia, quando foi morto por índios no Pantanal, em 1525, aproximadamente, estava voltando de uma expedição conquistadora no Chaco e trazia consigo um tesouro que ele havia pilhado de povos indígenas habitantes das terras baixas incaicas, na atual Bolívia.

A partir de então, uma série de subexpedições se desmembraram da grande expedição (aproximadamente 1500 espanhóis) de Pedro de Mendoza. Dentre essas sub-expedições, destaca-se aquela que esteve sob o comando do conquistador, Juan Domingos Ayolas. Ele foi um dos fundadores do Paraguai Colonial e é considerado pela história como aquele que transformou Assunção (fundada em 1537) em área estratégica para a conquista do Alto Paraguai, do Pantanal e do Chaco. Alguns anos depois, o adelantado Alvar Nunes Cabeza de Vaca comandou uma série de expedições de descobrimentos e conquistas: foi o descobridor do complexo lacustre das lagoas de Mandioré, Gaíba e Uberaba, onde esteve na época das cheias. A imensidão das águas interligadas (uma área de centenas de $\mathrm{km}^{2}$ ) fez com que os espanhóis denominassem o fenômeno hidrológico das inundações pantaneiras como "Mar dos Xaraés" (nome de uma etnia indígena que vivia ao redor dessas lagoas). Ainda nos meados do século XVI, Domingos Martinez Irala, conquistador castelhano paraguaio, comandou expedições exploratórias no atual território de Mato Grosso do Sul, sobretudo nas margens do rio Paraná, as quais resultaram, no início da segunda metade do século XVI, na fundação dos núcleos coloniais urbanos Ontiveros, Ciudad Real de Guairá e Vila Rica do Espírito Santo, cujas ruínas, hoje, encontram-se, a primeira em Mato Grosso do Sul, e as duas últimas no Estado do Paraná.

Os conquistadores espanhóis fizeram uma aliança com índios Guarani para dominar o Pantanal e o Chaco, na época densamente povoados por indígenas. Com isso, importaram as hostilidades dos tradicionais inimigos dos Guarani, entre eles os indígenas Guaikuru e outras etnias que viviam nessas regiões.

Essa aliança entre os espanhóis e os Guarani que viviam nos arredores de Assunção foi significativamente responsável pelo início do extermínio das populações indígenas do Pantanal. Depois, a esse processo de extermínio étnico, somaram-se, no século XVII, as diversas incursões dos bandeirantes paulistas. 
Eles, por exemplo, foram responsáveis pela extinção total dos índios Guarani que viviam no Pantanal, na região banhada pelos rios Miranda e Aquidauana. Naquela época, até a primeira metade do século XVII, dezenas de milhares de índios Guarani viviam no Pantanal. Hoje, não há mais essa presença étnica na área.

Dessa forma, também foram extintas outras etnias indígenas pantaneiras tais como os célebres Paiaguá, os quais detinham, até meados do século XVIII, hegemonia absoluta na navegação fluvial pelo médio curso do rio Paraguai e seus principais afluentes sul-mato-grossenses tais como o Taquari, o Miranda, o Apa e o Nabileque.

No município de Miranda localiza-se uma estação ferroviária, integrante da extinta E. F. Noroeste do Brasil, chamada Agachi. Esse topônimo é originário do etnômio dos também extintos índios Agachi. Como essa, talvez mais de uma dezena de etnias indígenas pantaneiras desapareceram em contato com o modelo colonizador ibérico na região durante os três primeiros séculos da colonização europeia do território brasileiro.

Dessas etnias restaram apenas os vestígios arqueológicos, tais como fragmentos de recipientes de cerâmica e de outros objetos. Essas são as evidências reais de que esses povos existiram, porém dos quais, hoje, não sabemos nem as suas denominações. Os arqueólogos atribuem a essas etnias alguns rótulos identitários, isto conforme seus procedimentos classificatórios.

Do ponto de vista da demografia nativa, a presença do "branco" no Pantanal foi realmente um fator dizimador, ao ponto de provocar um verdadeiro vácuo demográfico no Pantanal entre os séculos XVII e XVIII, sobretudo pelas incursões dos bandeirantes paulistas. Esse vácuo seria preenchido depois, no século XVIII, pelas incursões de etnias indígenas chaquenhas (Guaikuru e Guaná), as quais também estavam sendo pressionadas pela reacomodação territorial nativa no Chaco colonial. Essas etnias estavam sendo expulsas de seus territórios tradicionais no Chaco pela expansão espanhola.

Para se ter uma noção do impacto que a colonização ibérica causou na geografia humana nativa tradicional, podemos observar a situação dos índios Guató. Eles são, hoje, um exemplo do processo de como se deu a extinção dos indígenas pantaneiros. Os Guató representam atualmente talvez um dos últimos povos remanescentes dos imemoriais índios canoeiros do Pantanal. 
Um aspecto que estes povos tinham em comum era a capacidade de viver e se reproduzir, física e culturalmente, nesse ambiente, o qual, durante muito tempo, foi tido por observadores contemporâneos como inóspito ao ser humano. Os indígenas mostraram que isso não é verdade. A capacidade da humanidade em se adaptar a ambientes tão diversificados como as regiões geladas, onde vivem os esquimós, em desertos, como o Saara, e em extensas áreas inundadas como o Pantanal, mostram a criatividade das culturas humanas em desenvolver sistemas de interação e respostas às equações ambientais, mesmo portando diferentes identidades étnicas. Parafraseando o nome de uma exposição científica realizada em Paris, em 1992, na humanidade "somos todos parentes, todos diferentes".

Por meio da arqueologia, da etno-história e da etnografia percebe-se que povos com culturas diferentes viveram num mesmo ambiente. Isso é surpreendente e serve para derrubar o mito de que o homem é um produto do meio. Pelo contrário, ele se relaciona dialeticamente com o meio, isto a partir da sua forma de representar e simbolizar a realidade. As etnias indígenas pantaneiras, com diferentes visões de mundo, diversos modos de ser, se relacionaram e viveram no Pantanal durante séculos, talvez até milênios. Porém, cada uma desenvolveu sistemas culturais próprios, ou seja, línguas, mitos, ferramentas, dietas alimentares, procedimentos medicinais, padrões de sepultamento, enfim tudo aquilo que caracteriza os vários itens de um sistema cultural.

A expansão do domínio português tinha na ação dos missionários um dos pilares da "civilização" das nações indígenas, sobretudo para a constituição de stocks de mão-de-obra para a economia colonial.

Até o fim do século XIX, a política indigenista executada pela sociedade envolvente passou por três momentos distintos: entre 1500 e 1755, predominou a missionária; entre 1755 a 1789, prevaleceu a administração civil; e entre 1789 a 1845, preponderaram as expedições punitivas e a expansão das frentes agrícolas e pecuárias.

Após 1845, surgem as primeiras medidas para se evitar a violência exacerbada contra as populações indígenas. Nesse contexto foi fundado, em 1851, por frei Mariano de Bagnaia, a missão denominada Nossa Senhora do Bom Conselho, que perdurou até 1859 e foi totalmente destruída durante a guerra do Paraguai, em 1864. 
Peixoto e Schmitz ${ }^{14}$ confirmaram os relatos da crônica histórica quanto à existência da Missão Nossa Senhora do Bom Conselho, no Pantanal sul-mato-grossense, hoje município de Corumbá. Localizada pela visualização de um cruzeiro de aroeira em uma mata preservada na região denominada, pelos Guaná (Kinikinao), como Mato Grande, nessa Missão viviam cerca de 700 índios, como informou o capitão da província, João Crispiniano Soares, ao ministério do Império em 12/05/1847.

Alfredo Sganzela ${ }^{15}$, utilizando informações do diário de frei Mariano de Bagnaia, situava a missão Nossa Senhora do Bom Conselho a três léguas de Albuquerque. Através das informações históricas e das técnicas utilizadas pela Arqueologia, tais como levantamento de campo e análise da cultura material, foi possível fazer coincidir as informações das duas fontes e localizar as ruínas da missão nas margens da lagoa de Mato Grande, a 17 km do distrito de Albuquerque, no município de Corumbá.

No sítio histórico Missão da Nossa Senhora do Bom Conselho (área dos sítios MS-CP-39 e MS-CP-40), foi localizada citada cruz de madeira. Efetuou-se uma datação radiométrica em um fragmento de madeira (amostra Beta-221723) que comprovou a idade 1430 a 1660 AD. (séculos XV a XVII). Portanto, pode-se interpretar que a madeira foi reutilizada pelos missionários, vários anos após o seu corte ${ }^{16}$.

Já no século XIX, o contexto da base da morraria do Urucum foi palco para um balneário recreativo e terapêutico e, posteriormente, sediou uma usina de açúcar, cujas ruínas, hoje, integram um sítio histórico tombado pelo IPHAN (ver figura 10).

\footnotetext{
${ }^{14}$ PEIXOTO, José L. S.; SCHIMTZ, Pedro I. Missão de Nossa Senhora do Bom Conselho, Pantanal, Mato Grosso do Sul. São Leopoldo: UNISINOS, 1998 (Pesquisas, série História, 30).

${ }^{15}$ SGANZERLA, Alfredo. A História de Frei Mariano de Bagnaia. Campo Grande: Edição FUCMT-MCC, 1992.

${ }^{16}$ MARTINS, Gilson R. \& KASHIMOTO, Emília M. Projeto: Arqueologia preventiva na área impactada pela ampliação da mina DNPM 807204/71, Corumbá/MS. Campo Grande: FAPEC/ Vetorial Siderurgia Ltda., 2005. (não publicado).
} 


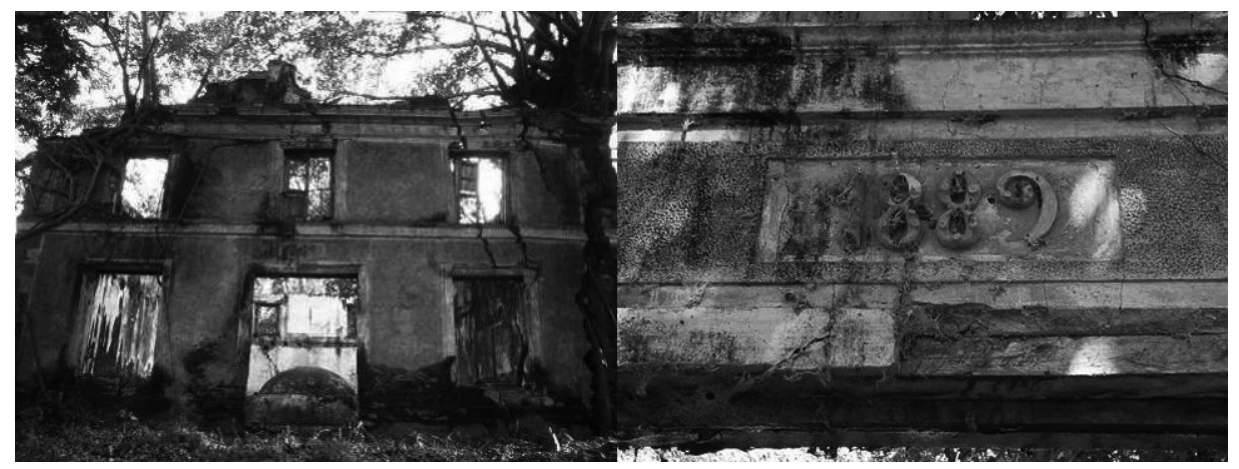

Figura 10: Ruínas históricas da Fazenda e Usina Urucum (1889)

Nas partes elevadas do maciço do Urucum, tanto a altitude, centenas de metros acima de sua base, como a aguda declividade da superfície, o solo rochoso e a distância de mananciais foram impeditivos para qualquer tipo de assentamento/ aldeamento indígena permanente. Porém, na perspectiva de preservação do Patrimônio Cultural, existe ainda as instalações da antiga mina da empresa Belgo-mineira, a qual se instalou no maciço no início do século XX. Hoje, as galerias e outras instalações não estão mais em uso, no entanto, possuem grande relevância para a história sócio-econômica de Corumbá, bem como para o entendimento dos processos de transformação, sob o viés econômico, da paisagem do maciço do Urucum. 